\title{
Cigarette smoking in Poland in 2019: the continuing decline in smoking prevalence
}

\author{
Kinga Janik-Koncewicz' , Witold Zatoński', Katarzyna Zatońska², Zuzanna Stępnicka², \\ Alicja Basiak-Rasała ${ }^{2}$, Mateusz Zatoński ${ }^{1,3}$, Katarzyna Połtyn-Zaradna ${ }^{2}$ \\ IInstitute - European Observatory of Health Inequalities, Calisia University, Kalisz, Poland \\ 2Department of Social Medicine, Wroclaw Medical University, Poland \\ ${ }^{3}$ Tobacco Control Research Group, Department for Health, University of Bath, United Kingdom
}

\begin{abstract}
The aim of the study: To present comprehensive national estimates of prevalence of cigarette smoking by sociodemographic characteristics in Poland in 2019 and to analyse the changes in smoking prevalence in the Polish population after 2014.

Material and methods: A cross-sectional survey on a representative sample of adult Polish population was conducted on 4-11 July 2019 by the Public Opinion Research Center (Centrum Badania Opinii Społecznej). A total of 1016 adults ( $42.4 \%$ men and $57.6 \%$ women) aged 20 years and older were included in the analysis. Data for smoking prevalence were analysed according to gender, age groups, birth cohorts, place of residence and education. Statistical analysis was done using Statistica 13.1 and assumed a significance level of $p<0.05$.

Results: Of the total sample population, $21.8 \%$ of Polish adults declared they are daily smokers (in the general population this would translate to 6.8 million Poles, including 3.9 million men and 2.9 million women), $27.8 \%$ that they are ex-smokers and $50.4 \%$ that they never smoked tobacco. More men than women declared they are daily smokers ( $26.9 \%$ vs $18.1 \%)$ and ex-smokers ( $36.2 \%$ vs $21.5 \%)$, and women were more likely to declare they are never smokers than men (60.3\% vs $36.9 \%)$.

Conclusions: Poland has experienced a decrease in smoking prevalence since 1976 in men and since 1982 in women. In 2019 the most important factor shaping smoking prevalence in Poland was education. Sex differences in smoking rates have been converging since late 1970s. Those with lower levels of education, as well as middle-aged men and women (45-64 years old) were found to have the highest levels of daily smoking and should be offered targeted support promoting smoking cessation. There is an urgent need to bring back and strengthen a national tobacco control strategy in Poland. This should include systematic annual surveys of smoking behaviours on a representative sample of Polish population using a standardised methodology.
\end{abstract}

KEY WORDS: tobacco, cigarettes, smoking prevalence, Poland.

ADDRESS FOR CORRESPONDENCE: Kinga Janik-Koncewicz, Institute - European Observatory of Health Inequalities, Calisia University, 4 Nowy Świat St., 62-800 Kalisz, Poland, e-mail: k.janik-koncewicz@akademiakaliska.edu.pl

\section{INTRODUCTION}

Tobacco smoking is one of the leading avoidable causes of premature mortality worldwide. According to the World Health Organization (WHO) there are 1.3 billion tobacco users in the world and each year tobacco causes over 8 million of deaths [1]. However, large differences exist in smoking prevalence between countries. In the WHO European region there are countries with relatively low age-standardised rates of current cigarette smoking, such as Iceland (11.0\%), Sweden (12.4\%) or Norway (14.6\%) and those with some of the highest smoking prevalence in the world, including Serbia (36.2\%), 
Bulgaria (35.8\%) and Greece (35.6\%) [2]. In Poland, cigarette consumption decreased from around 3,000 cigarettes per annum per capita in 1980 (one of the highest levels ever recorded globally) to under 1,300 cigarettes in 2019 [3-5]. Peto et al. estimated 85,000 deaths attributable to tobacco in Poland for 2015 [6]. The latest estimation done by Samet and Buran for Poland in 2017 showed around 80,000 deaths attributable to smoking [7].

Poland has been monitoring cigarette smoking prevalence since 1974, which makes it one of the countries with the longest systematic observation periods of smoking prevalence in Europe [4,8]. The MPOWER policy package, developed in 2008 to assist countries in implementing the provisions of the WHO Framework Convention on Tobacco Control, includes monitoring tobacco use as its first core component [9]. It advises that countries develop a system of obtaining good quality, nationally representative and population-based periodic data on key indicators of tobacco use for youth and adults. Effective surveillance and monitoring can help determine the size and nature of the tobacco epidemic and plan effective strategies and policies. Accurately measuring the number of smokers in a country allows to predict and map the long-term public health consequences of tobacco use in the population and their impact on the health indicators. For example, Poland's historical reduction in smoking rates led to a decrease in lung cancer mortality among Polish young and middle-aged men and women (who have shorter delay time

TABLE 1. Descriptive characteristics of the study population

\begin{tabular}{|c|c|c|}
\hline Characteristics & Percentage & $n$ \\
\hline Overall & 100 & 1016 \\
\hline \multicolumn{3}{|l|}{ Gender } \\
\hline Men & 42.4 & 431 \\
\hline Women & 57.6 & 585 \\
\hline \multicolumn{3}{|l|}{ Age } \\
\hline 20-44 years & 37.6 & 382 \\
\hline $45-64$ years & 33.3 & 338 \\
\hline 65 years and older & 29.1 & 296 \\
\hline \multicolumn{3}{|l|}{ Residence } \\
\hline Urban & 61.0 & 620 \\
\hline Rural & 39.0 & 396 \\
\hline \multicolumn{3}{|l|}{ Education } \\
\hline $\begin{array}{l}\text { Primary } \\
\text { and gymnasium }\end{array}$ & 15.2 & 154 \\
\hline Vocational & 25.4 & 258 \\
\hline Secondary & 34.1 & 347 \\
\hline Higher/academic & 25.3 & 257 \\
\hline
\end{tabular}

$n$-sample size in comparison with older age groups) and cardiovascular mortality in all ages and in both sexes [4, 10-12].

The aim of this study is to assess comprehensive national estimates of cigarette smoking prevalence by sociodemographic characteristics in Poland in 2019 and to analyse the changes in exposition to cigarette smoking in the Polish population after 2014.

\section{MATERIAL AND METHODS}

The data analysed in this study comes from a cross sectional study with multitask approach "Actual problems and events" ("Aktualne problemy i wydarzenia") conducted by the Public Opinion Research Center (Centrum Badań Opinii Społecznej) on 4-11 July 2019 on a representative sample of 1077 adult Polish population aged 18 years or older [13]. Face-to-face interviews were carried out using the computer-assisted personal interviewing (CAPI) technique [14]. A random sample was selected from the register of personal identity numbers containing information on every Polish citizen registered in Poland. The sampling frame included stratification according to territorial localization, size of the place of residence, gender and age. The sampling frame ensured that the study sample corresponded with the structure of the general Polish population in 2019.

The analysis in this article includes respondents aged 20 years and older (1016 respondents) who responded to the question about smoking behaviours. Occasional smokers (48 respondents) and those below 20 years of age (13 respondents) were excluded from the analysis. The analysis focused on daily smokers instead of occasional smokers, as the latter are a heterogenous and small group for which further analysis and stratification would not yield significant results. Detailed socio-demographic characteristics of the study population are presented in Table 1.

The questionnaire included two questions concerning cigarette smoking: (1) "Do you smoke cigarettes? We refer to traditional cigarettes, not electronic cigarettes", with multiple choice answers: (a) "Yes, regularly", (b) "Yes, but only in exceptional situations, occasionally", (c) "No"; (2) "Have you smoked cigarettes in the past?", with multiple choice answers: "Yes" or "No". Based on the responses to these questions the study population was divided into three categories of smoking status: daily smokers, ex-smokers and never smokers. The number of smokers, ex-smokers and never smokers in the general Polish population was extrapolated using data on the population of Poland aged 20 years and older on 31.12.2019 provided by the National Statistical Office. Data were analysed according to gender, age groups ( $\geq 20$ years, $20-44$ years, $45-64$ years, $\geq 65$ years,), birth cohort (born before 1940, born between 1940 and 1959, born between 1960 and 1980, born after 1980), place of residence (urban or rural) and education (1) prima- 
ry and incomplete, (2) vocational, (3) secondary and (4) higher/academic.

The distribution of variables concerning smoking behaviours for men and women was delivered by frequencies and proportions with $95 \%$ confidence intervals calculated using the Clopper-Pearson method for binomial confidence intervals. Association between sociodemographic factor and smoking was assessed using adjusted logistic regression models after stratifying for gender. The strength of the association was measured by the odds ratio (OR) with $95 \%$ confidence intervals. Despite the very small size, the birth cohort $<1940$ was adopted as a reference group to reflect the observed changes in smoking behaviours over the years in the Polish population. Statistical analysis was done using Statistica 13.1 and assumes significance level $p<0.05$.

\section{RESULTS}

Of the total sample population aged 20 years and older $21.8 \%$ were daily smokers, $27.8 \%$ were ex-smokers and $50.4 \%$ never smoked tobacco. Men were more likely than women to be daily smokers $(26.9 \%$ vs $18.1 \%)$ and ex-smokers (36.2\% vs $21.5 \%)$. Sixty percent $(60.3 \%)$ of women and $36.9 \%$ of men were never smokers (Table 2 ).

Tables 3 and 4 present smoking prevalence by sociodemographic factors in both sexes. In men, the highest percentage of daily smokers was found in the 45-64 age group (30.4\%) and the lowest in the oldest age group (22.0\% of men aged 65 years and older). The older the age group, the lower the proportion of ex-smokers and the higher the proportion of never smokers among men. The percentage of daily smokers was the highest in the 1960-1980 birth cohort (32.0\%), and the lowest in the oldest birth cohort of men born before 1940 (14.0\%), while there were more than $50 \%$ ex-smokers among men born before 1960 and fewer than $20 \%$ among those born after 1980. The study found the highest percentage of daily smokers in men with primary education (49.2\%), and the lowest smoking prevalence in men with higher education $(8.3 \%)$. In men with higher education there was also the highest percentage of ex-smokers (39.5\%) and never smokers (52.1\%) (Table 3).
In women the highest prevalence of daily smoking was also found in the 45-64 age group (28.3\%) and the lowest in the oldest (65+) age group (11.6\%). The lowest percentage of ex-smokers was in the youngest age group of women (16.2\%, 20-44 years old) in comparison with middle-aged women $(25.7 \%, 45-64$ years old) and the oldest ones $(23.8 \%, 65$ years and older). There was a higher percentage of never smoking women in the 20-44 age group (69.4\%) and among those aged 65 and older (64.6\%), than in the 45-64 age group (46.0\%). The highest percentage of daily smokers was found in women born between 1960 and 1980 (23.5\%), the highest percentage of ex-smokers among women born before 1960 and, the highest percentage of never smokers among women born before 1940 (75.0\%) and after 1980 (70.4\%). The lowest percentage of daily smokers was found in women with the lowest (primary education) and the highest (higher education) level of education (12.4\% and $13.4 \%)$. The highest smoking prevalence was found in women with vocational education (28.8\%). Most ex-smokers could be found among women with vocational and secondary education (25.3\% and $24.4 \%$ ), in comparison with $14.8 \%$ among those with higher education. The study found the highest percentage of never smokers among women with higher education (71.8\%) (Table 4).

Urban or rural residence did not differentiate significantly smoking behaviours in the study in both men and women (Tables 3 and 4). Analysis showed the lowest odds of daily smoking in men aged 65 and older, in comparison with the youngest age group (20-44 years). In women there were higher odds of daily smoking in the 45-64 age group compared to the 20-44 age group. In women, there were higher odds of daily smoking among those with vocational education compared to primary education (lowest level of education). The odds of daily smoking were lower in women aged 65 years and older, born after 1980, and with secondary education (Tables 3 and 4).

\section{DISCUSSION}

In 2019 in both sexes the most important factor affecting smoking prevalence in Poland was education. The lower the education level, the higher the prevalence

TABLE 2. Smoking prevalence in Poland in 2019

\begin{tabular}{|l|c|c|c|c|c|c|c|c|c|}
\hline \multirow{2}{*}{$\begin{array}{l}\text { Charac- } \\
\text { teristics }\end{array}$} & \multicolumn{3}{|c|}{ Total } & \multicolumn{5}{c|}{ Men } & \multicolumn{3}{c|}{ Women } \\
\cline { 2 - 10 } & $n$ & $\begin{array}{c}\% \\
(95 \% \mathrm{Cl})\end{array}$ & $N$ & $n$ & $\begin{array}{c}\% \\
(95 \% \mathrm{Cl})\end{array}$ & $N$ & $n$ & $\begin{array}{c}\% \\
(95 \% \mathrm{Cl})\end{array}$ & $N$ \\
\hline $\begin{array}{l}\text { Daily } \\
\text { smokers }\end{array}$ & 222 & $\begin{array}{c}21.8 \\
(19.4-24.5)\end{array}$ & $6,848,420$ & 116 & $\begin{array}{c}26.9 \\
(22.8-31.3)\end{array}$ & $3,936,984$ & 106 & $\begin{array}{c}18.1 \\
(15.1-21.5)\end{array}$ & $2,911,436$ \\
\hline $\begin{array}{l}\text { Ex- } \\
\text { smokers }\end{array}$ & 282 & $\begin{array}{c}27.8 \\
(25.1-30.6)\end{array}$ & $8,756,434$ & 156 & $\begin{array}{c}36.2 \\
(31.6-40.9)\end{array}$ & $5,298,098$ & 126 & $\begin{array}{c}21.5 \\
(18.3-25.1)\end{array}$ & $3,458,336$ \\
\hline $\begin{array}{l}\text { Never } \\
\text { smokers }\end{array}$ & 512 & $\begin{array}{c}50.4 \\
(47.3-53.5)\end{array}$ & $15,099,973$ & 159 & $\begin{array}{c}36.9 \\
(32.3-41.6)\end{array}$ & $5,400,547$ & 353 & $\begin{array}{c}60.3 \\
(56.3-64.3)\end{array}$ & $9,699,426$ \\
\hline
\end{tabular}

$n$-sample size, $\mathrm{Cl}$ - confidence interval, $\mathrm{N}$ - estimated number in general Polish population 
TABLE 3. Tobacco smoking by sociodemographic factors in men $(n=431)$

\begin{tabular}{|c|c|c|c|c|c|c|c|c|c|c|c|}
\hline \multirow[t]{2}{*}{ Parameter } & \multicolumn{4}{|c|}{$\begin{array}{l}\text { Daily smokers } \\
\qquad(n=116)\end{array}$} & \multicolumn{4}{|c|}{$\begin{array}{l}\text { Ex-smokers } \\
(n=156)\end{array}$} & \multicolumn{2}{|c|}{$\begin{array}{l}\text { Never smokers } \\
\quad(n=159)\end{array}$} & \multirow[t]{2}{*}{$p$-value } \\
\hline & $n$ & $\%$ & OR $^{*}$ & $95 \% \mathrm{Cl}$ & $n$ & $\%$ & OR* & $95 \% \mathrm{Cl}$ & $n$ & $\%$ & \\
\hline \multicolumn{12}{|l|}{ Age } \\
\hline $\begin{array}{l}20-44 \\
\text { years }\end{array}$ & 46 & 28.1 & \multicolumn{2}{|c|}{ Ref 1} & 34 & 20.4 & \multicolumn{2}{|c|}{ Ref 1} & 85 & 51.5 & \multirow[t]{3}{*}{$<0.001$} \\
\hline $\begin{array}{l}45-64 \\
\text { years }\end{array}$ & 45 & 30.4 & 1.19 & $0.73-1.94$ & 56 & 40.2 & 1.68 & $0.93-3.04$ & 42 & 29.4 & \\
\hline $\begin{array}{l}65 \text { and } \\
\text { older }\end{array}$ & 25 & 22.0 & 0.56 & $0.32-0.98$ & 66 & 51.7 & 2.12 & $1.16-3.88$ & 32 & 26.3 & \\
\hline \multicolumn{12}{|l|}{ Birth cohort } \\
\hline$<1940$ & 2 & 14.0 & \multicolumn{2}{|c|}{ Ref 1} & 9 & 52.8 & \multicolumn{2}{|c|}{ Ref 1} & 5 & 33.2 & \multirow[t]{4}{*}{0.001} \\
\hline 1940-1959 & 34 & 23.8 & 2.18 & $0.47-10.09$ & 76 & 53.1 & 0.50 & $0.10-2.42$ & 33 & 23.1 & \\
\hline $1960-1980$ & 48 & 32.0 & 1.51 & $0.90-2.53$ & 47 & 31.3 & 0.44 & $0.25-0.77$ & 55 & 36.7 & \\
\hline$>1980$ & 32 & 26.2 & 0.74 & $0.44-1.24$ & 24 & 19.7 & 0.72 & $0.37-1.39$ & 66 & 54.1 & \\
\hline \multicolumn{12}{|c|}{ Level of education } \\
\hline Primary & 32 & 49.2 & \multicolumn{2}{|c|}{ Ref 1} & 22 & 33.8 & \multicolumn{2}{|c|}{ Ref 1} & 11 & 16.9 & \multirow[t]{4}{*}{$<0.001$} \\
\hline Vocational & 46 & 32.9 & 0.54 & $0.31-0.93$ & 52 & 37.1 & 1.75 & $0.90-3.40$ & 42 & 30.0 & \\
\hline Secondary & 31 & 24.2 & 0.63 & $0.37-1.08$ & 42 & 30.2 & 1.20 & $0.65-2.21$ & 57 & 45.6 & \\
\hline Higher & 7 & 8.3 & 0.51 & $0.32-0.81$ & 40 & 39.5 & 4.22 & $1.67-10.66$ & 49 & 52.1 & \\
\hline \multicolumn{12}{|c|}{ Place of residence } \\
\hline Urban & 64 & 24.9 & \multirow[t]{2}{*}{0.77} & \multirow[t]{2}{*}{$0.50-1.19$} & 101 & 39.3 & \multirow[t]{2}{*}{1.45} & \multirow[t]{2}{*}{$0.89-2.36$} & 92 & 35.8 & \multirow[t]{2}{*}{$>0.05$} \\
\hline Rural & 52 & 28.8 & & & 55 & 29.0 & & & 67 & 42.2 & \\
\hline
\end{tabular}

$n$ - sample size, $O R$ - odds ratio, $\mathrm{Cl}$ - confidence interval, Ref - referenced group, OR ${ }^{*}$ daily smokers vs ex-smokers and never smokers, $O R^{* *}$ ex-smokers vs daily smokers

of smoking in men. Almost half of all men with primary education (49.2\%) were daily smokers, as was one in three men with vocational education $(32.9 \%)$, and one in four men with secondary education (24.2\%). Men with the highest education level had the lowest smoking prevalence $(8.3 \%)$ - this is the first demographic group to reach a level of smoking recommended by the WHO [15]. Education was important in determining smoking prevalence among women in Poland as well, but the pattern of smoking according to education was different then in men. The lowest prevalence of daily smoking was observed among women with the highest (13.4\%) and lowest (12.4\%) levels of education. In the group of women with secondary education $18.0 \%$ smoked daily. The highest prevalence of daily smoking was found in women with vocational education $(28.8 \%)$. This study therefore adds to the body of research showing that in the Polish population both men and women with primary and vocational education are at the highest risk of smoking and, in result, poor health. These groups have also been found to engage in heavier smoking behaviours, in particular men [16]. This study indicates that education inequalities are a key risk factor shaping access to good health in Poland.
The second important factor linked with cigarette smoking is age and the birth cohort. The highest prevalence of smoking in both sexes was observed in the 45-64 age group. Interestingly, the prevalence of smoking in this age group is very similar in men and women ( $30.4 \%$ vs $28.3 \%$, male-to-female smoking prevalence ratio 1.07). However, the most striking differences in smoking prevalence among men and women were found in the $20-44$ age group, in which $28.1 \%$ of men compared to $14.4 \%$ of women smoked cigarettes daily (ratio 1.95 ). We observed a similar difference between sexes in the oldest age group (65 and older) in which $22 \%$ of men and $11.6 \%$ of women were daily smokers (ratio 1.90 ). The finding that the highest prevalence of smoking persists in the middle-aged population should inform the planning of tobacco control activities and development of targeted cessation programmes in Poland.

In past studies, place of residence (urban or rural) was identified as an important factor determining smoking prevalence in Poland, as smoking rates among women in urban areas were found to be higher than in rural areas [4]. In this study the place of residence was not significantly associated with smoking prevalence. 
TABLE 4. Tobacco smoking by sociodemographic factors in women $(n=585)$

\begin{tabular}{|c|c|c|c|c|c|c|c|c|c|c|c|}
\hline \multirow[t]{2}{*}{ Parameter } & \multicolumn{4}{|c|}{$\begin{array}{l}\text { Daily smokers } \\
\qquad(n=106)\end{array}$} & \multicolumn{4}{|c|}{$\begin{array}{l}\text { Ex-smokers } \\
\qquad(n=126)\end{array}$} & \multicolumn{2}{|c|}{$\begin{array}{c}\text { Never smo- } \\
\text { kers } \\
(n=353)\end{array}$} & \multirow[t]{2}{*}{$p$-value } \\
\hline & $n$ & $\%$ & $\mathrm{OR}^{*}$ & $95 \% \mathrm{Cl}$ & $n$ & $\%$ & OR** & $95 \% \mathrm{Cl}$ & $n$ & $\%$ & \\
\hline \multicolumn{12}{|l|}{ Age } \\
\hline 20-44 years & 31 & 14.4 & \multicolumn{2}{|c|}{ Ref 1} & 34 & 16.2 & \multicolumn{2}{|c|}{ Ref 1} & 152 & 69.4 & \multirow[t]{3}{*}{0.001} \\
\hline $45-64$ years & 54 & 28.3 & 2.30 & $1.40-3.76$ & 52 & 25.7 & 0.88 & $0.47-1.63$ & 89 & 46.0 & \\
\hline $\begin{array}{l}65 \text { and } \\
\text { older }\end{array}$ & 21 & 11.6 & 0.36 & $0.21-0.63$ & 40 & 23.8 & 1.98 & $1.03-3.79$ & 112 & 64.6 & \\
\hline \multicolumn{12}{|l|}{ Birth cohort } \\
\hline$<1940$ & 0 & 0 & \multicolumn{2}{|c|}{ Ref 1} & 6 & 25.0 & \multicolumn{2}{|c|}{ Ref 1} & 18 & 75.0 & \multirow[t]{4}{*}{0.03} \\
\hline 1940-1959 & 35 & 17.9 & 10.77 & $0.64-181.33$ & 52 & 26.5 & 0.11 & $0.01-2.08$ & 109 & 55.6 & \\
\hline 1960-1980 & 46 & 23.5 & 1.41 & $0.86-2.31$ & 43 & 21.9 & 0.63 & $0.35-1.14$ & 107 & 54.6 & \\
\hline$>1980$ & 25 & 14.8 & 0.55 & $0.32-0.94$ & 25 & 14.8 & 1.07 & $0.54-2.14$ & 119 & 70.4 & \\
\hline \multicolumn{12}{|c|}{ Level of education } \\
\hline Primary & 11 & 12.4 & \multicolumn{2}{|c|}{ Ref 1} & 17 & 19.1 & \multicolumn{2}{|c|}{ Ref 1} & 61 & 68.5 & \multirow[t]{4}{*}{$<0.001$} \\
\hline Vocational & 34 & 28.8 & 2.94 & $1.40-6.20$ & 29 & 25.3 & 0.28 & $0.13-0.61$ & 55 & 45.9 & \\
\hline Secondary & 39 & 18.0 & 0.53 & $0.32-0.91$ & 53 & 24.4 & 2.01 & $1.15-3.52$ & 125 & 57.6 & \\
\hline Higher & 22 & 13.4 & 0.73 & $0.41-1.29$ & 27 & 14.8 & 1.56 & $0.87-2.80$ & 112 & 71.8 & \\
\hline \multicolumn{12}{|c|}{ Place of residence } \\
\hline Urban & 70 & 20.2 & \multirow[t]{2}{*}{1.26} & \multirow[t]{2}{*}{$0.81-1.96$} & 81 & 21.6 & \multirow[t]{2}{*}{0.3} & \multirow[t]{2}{*}{$0.54-1.59$} & 212 & 58.2 & \multirow[t]{2}{*}{$>0.05$} \\
\hline Rural & 36 & 16.2 & & & 45 & 20.3 & & & 141 & 63.5 & \\
\hline
\end{tabular}

$n$ - sample size, OR - odds ratio, Cl - confidence interval, Ref - referenced group, OR* daily smokers vs ex-smokers and never smokers, $O R^{* *}$ ex-smokers vs daily smokers

Historically, the most important factor determining smoking prevalence was sex. Smoking rates in the 20th century were several times higher among men than women [4]. This study found that smoking prevalence remains higher among men than women in Poland, but that the ratio of male-to-female smoking prevalence (1.5) is significantly lower compared to the years 1960 1980 (in 1974 the ratio was 3.3) [4]. This finding places Poland alongside most Central and Western European countries where ratio of male-to-female smoking prevalence is around 2 or less (i.e. 2.1 in Latvia, 1.5 in Slovakia, 1.4 in Italy, 1.2 in Netherlands, 1.0 in Norway), in contrast to many Eastern European countries, where ratios are much higher - 4 in Ukraine and far more, 10.3 in Georgia, 34.7 in Armenia, and more than 100 in Azerbaijan [2]. Generally, in Asian countries prevalence of smoking in women is very low, far lower than prevalence of smoking among men. Thus contrary to European countries, male-to-female smoking prevalence ratios in these countries, are very high, for example in China smoking prevalence among women is around $2 \%$ and among men 53\%, and the ratio is $26.5[17,18]$.

Results from another study conducted in 2019 in Poland by Kantar Public for the Chief Sanitary Inspector
[19] on a representative nationwide sample of around 1000 individuals aged $15+$ showed that the percentage of daily smokers was $21.0 \%$ (24.4\% men and $18.0 \%$ women), the percentage of ex-smokers was $10.7 \%$, and of never smokers was $67.0 \%$. These results correspond with the findings of this study and the ratio of male-tofemale smoking prevalence was comparable. A higher proportion of daily smokers was found among men than women in both studies. The Kantar study also showed that education level is the strongest factor associated with daily smoking. Lower education level (compared to higher education) in both men and women was significantly associated with daily smoking (OR 3.03, 95\% CI $1.75-5.26, p<0.001)$. However, it must be underlined that there were some differences in study population according to age (in our study the population was 20 years and older, in the Kantar study it was 15 years and older; in addition both studies selected different age groups for analysis), methodology (i.e. different questions about smoking were used in the questionnaires), data analysis and presentation (i.e. the Kantar study analysed daily smoking by socioeconomic factors in both sexes together), thus comparing results from these studies should be done with caution. Nevertheless, results from both 
studies correspond to findings from most other European countries where education has also been identified as a strong predictor of smoking status [20], and where sex is no longer the most important factor determining smoking behaviours [2].

Our study confirms the ongoing pattern of decreasing smoking prevalence in Poland that has been observed for the past decades. It must be mentioned that smoking in Poland concerns almost exclusively cigarettes, which constitutes $99 \%$ of tobacco use [4]. The decline in cigarette smoking prevalence in Poland began in the male population in 1976 and in women in 1982 [4]. The findings of this study contrast with several recent publications suggesting that the decrease in smoking prevalence in Poland has stopped after 2014 [21,22]. These discrepancies might be partially explained by the fact that annual surveys on smoking behaviours in Poland are conducted on relatively small samples of population (approx. 1000 respondents), with a relatively high standard error, or using different sampling methods. Additionally, some recent publications have been conflating conventional cigarettes with nicotine delivery devices (so called e-cigarettes, nicotine vaporisers) [21].

The Global Burden Disease (GBD) Tobacco Collaborators in 2017 published an analysis of worldwide trends of changes in estimates of smoking prevalence and its health consequences between 1990 and 2015 [23] based on mathematical models following the overall GBD 2015 comparative risk assessment framework [24]. They found that in 1990 the level of tobacco smoking in Poland was one of the highest in Europe. Among European countries, Poland was found in 2015 in the middle of the ranking list of smoking prevalence ( $26.7 \%$ of daily smokers in men and $19.3 \%$ in women). The GBD analysis showed that Poland had one of the fastest smoking prevalence declines in Europe between 1990 and 2015 [4, 23, 25, 26].

The MPOWER strategy to reduce global tobacco use underlines that countries need specific data of tobacco use to plan tobacco control strategies and effective interventions. Population surveys should use representative, random, and efficiently large sample. Questionnaire surveys should be repeated at regular time periods, using the same methodology (questions, data analysis and reporting techniques) to enable comparability of data across different years. This "golden standard" requires that appropriate data collecting systems are established and maintained, and that they use standardized and scientifically valid data collection methods and analysis practices. Only with such a system in place can a country conduct an accurate impact assessment of tobacco smoking in the population, develop appropriate tobacco control interventions activities, and correctly assess their effectiveness over time.

It is worth underlining that Poland was among the countries pioneering golden standards in the monitoring of smoking prevalence already in 1970s [27]. However, the regular surveys on tobacco smoking behaviours carried out since 1982 by the Department of Epidemiology and Prevention in Cancer Center and Institute of Oncology in Warsaw have been discontinued in 2014, and in recent years there has been no systematic monitoring of smoking rates in Poland that would be based on homogeneous criteria for sampling frame and questionnaire.

The lack of a homogeneous definition of individual smoking behaviours makes it difficult to compare results across surveys. For example, in the WOBASZ study (20032014) [28] a current smoker was defined as a person who regularly smoked at least 1 cigarette a day, an occasional smoker as someone who smokes less than 1 cigarette per day, and an ex-smoker as a person who smoked in the past, stopped smoking and did not smoke during the survey, and a non-smoker as a person who has never smoked. On the other hand, in the 6-year follow-up of the PURE Poland Study [29], current smokers were defined as those who had smoked in their lifetime at least 100 cigarettes and currently smoke cigarettes every day or occasionally, while never smokers as those who had never smoked or smoked fewer than 100 cigarettes in their lifetime.

The decreasing trend of smoking prevalence in Poland and examples of effective tobacco control programmes from other European countries are a good illustration of how progress can be made in combatting smoking and, in result, smoking-related diseases. After introducing a set of strong regulations in the 1990s Poland was acknowledged as a leader of tobacco control in Europe [30]. However, more recent years brought some adverse changes that could affect smoking rates in Poland. In 2015 the national tobacco control programme was discontinued [4]. The government suspended the annual increase of tax on tobacco products. These examples of unfavourable decisions constitute a serious threat to public health, and risk exacerbating the burden of tobacco-related diseases in Poland.

It is necessary for Poland to reintroduce systematic annual surveys on smoking behaviours carried out on a representative sample the population, and using a standard questionnaires that would enable the precise definition of regular smokers, occasional smokers, ex-smokers and never smokers. Such surveys should include an assessment of the number of cigarettes smoked per day, the age of smoking initiation, the reasons for smoking cessation and the time of stopping smoking for good. The high-quality, in-depth data obtained from such studies would make it possible to develop personalized and more effective prevention programmes.

\section{CONCLUSIONS}

In 2019 the most important factor shaping smoking prevalence in Poland was education, while differences in smoking between men and women have been decreasing. Middle-aged men and women should be the group of special attention in planning tobacco control strategies. 
Prevalence of cigarette smoking has been decreasing in Poland in both men and women for several decades, however around 6.8 million Poles (3.9 million of men, 2.9 million of women) are still daily smokers. Only systematic and good quality surveys can lead to monitoring effective prevention policies. The decreasing trend of smoking prevalence in Poland and examples of effective tobacco control programmes from other European countries show that gains could be made. However, continuing this positive trend in Poland would require the immediate reintroduction of a comprehensive national tobacco control strategy and updating Poland's tobacco control legislation to reflect golden standard practices from around the world, including a complete ban on smoking in public places, plain packaging, and meaningful increases in cigarette taxation.

\section{ACKNOWLEDGEMENTS}

Authors of the manuscript would like to thank the Public Opinion Research Center (Centrum Badania Opinii Społecznej) for collaboration and data release.

\section{DISCLOSURE}

The authors report no conflict of interest.

\section{References}

1. World Health Organization. Tobacco. Key facts. Available from: https://www.who.int/news-room/fact-sheets/detail/tobacco (accessed: 8 October 2020).

2. World Health Organization. WHO global report on trends in prevalence of tobacco use 2000-2025. Third edition. Available from: https:/www.who.int/publications/i/item/who-global-report-ontrends-in-prevalence-of-tobacco-use-2000-2025-third-edition (accessed: 5 November 2020).

3. Hoffman SJ, Mammone J, Rogers Van Katwyk S, et al. Cigarette consumption estimates for 71 countries from 1970 to 2015: systematic collection of comparable data to facilitate quasiexperimental evaluations of national and global tobacco control interventions. BMJ 2019; 19: 12231.

4. Zatoński WA, Zatoński M, Janik-Koncewicz K, et al. Hundred years of cigarette smoking in Poland: three phases of the tobacco epidemic. J Health Inequal 2017; 3(2): 118-122.

5. National Statistical Office. Rynek wewnętrzny w 2019 r. [Internal market in 2019]. Available from: stat.gov.pl (accessed: 25 November 2020).

6. Peto R, Lopez AD, Pan $\mathrm{H}$, et al. Mortality from smoking in developed countries 1950-2020. Available from: https://gas. ctsu.ox.ac.uk/tobacco/SMK_P5_6.pdf (accessed: 10 November 2020).

7. Samet J, Buran M. The burden of avoidable disease from air pollution: implications for prevention. J Health Inequal 2020; 6 (1): 1-5.

8. Oleś P. The extent of tobacco use in Poland. World Smoking Health 1983; 8 (2): 38-44.

9. World Health Organization. MPOWER. A policy package to reverse the tobacco epidemic. World Health Organization, Geneva 2008.
10. Zatoński WA. One hundred years of health in Poland. J Health Inequal 2019; 5 (1): 11-19.

11. Zatonski WA, Bhala N. Changing trends of diseases in Eastern Europe: closing the gap. Public Health 2012; 126: 248-252.

12. Zatoński WA, Sulkowska U, Didkowska J. Kilka uwag o epidemiologii nowotworów w Polsce [Some comments on cancer epidemiology in Poland]. Nowotwory Journal of Oncology 2015; 65 (3): 179-196.

13. Centrum Badania Opini Społecznej. Komunikat z badań. Palenie papierosów. Nr 104/2019. Available from: https://cbos.pl/ SPISKOM.POL/2019/K_104_19.PDF (accessed: 14 February 2020).

14. Kissinger L, Lorenzana R, Mittl B, et al. Development of a computer-assisted personal interview software system for collection of tribal fish consumption data. Risk Anal 2010; 30 (12): 1833-1841.

15. World Health Organization. WHO report on the global tobacco epidemic, 2017. Monitoring tobacco use and prevention policies. Available from: https://apps.who.int/iris/bitstream/ handle/10665/255874/9789241512824-eng.pdf;jsessionid $=9$ CB83C254C21DDC9A634F0BC3BAA9817? sequence $=1$ (accessed: 20 November 2020).

16. Pikala M, Burzyńska $M$, Pikala R, et al. Educational inequalities in premature mortality in Poland, 2002-2011: a population-based cross-sectional study. BMJ Open 2016; 6: e011501.

17. Palipudi KM, Gupta PC, Sinha DN, Andes LJ, Asma S, McAfee T, on behalf of the GATS Collaborative Group (... Zatoński W, Przewoźniak K.). Social determinants of health and tobacco use in thirteen low and middle income countries: evidence from Global Adult Tobacco Survey. PLoS One 2012; 7 (3): e33466.

18. Stelmach M, Janik-Koncewicz K, Herbeć A, et al. Give it up! - a new mobile app and campaign supporting women to quit smoking in Poland - project rationale and app description. J Health Inequal 2018; 4 (1): 23-26.

19. Pinkas J, Kaleta D, Zgliczyński WS, et al. The prevalence of tobacco and e-cigarette use in Poland: a 2019 nationwide cross-sectional survey. Int J Environ Res Public Health 2019; 16 (23): 4820.

20. Huisman M, Kunst AE, Mackenbach JP. Inequalities in the prevalence of smoking in the European Union: comparing education and income. Prev Med 2005; 40 (6): 756-764.

21. Wojtyniak B, Goryński P (eds). Sytuacja zdrowotna ludności Polski i jej uwarunkowania. Available from: https://nas-hcv.pzh. gov.pl/file/sharing/5hLdR8CUo (accessed: 10 November 2020).

22. Krzyżanowski M. Comments on "The burden of avoidable disease from air pollution: implications for prevention". J Health Inequal 2020; 6 (2): 26-27.

23. GBD 2015 Tobacco Collaborators. Smoking prevalence and attributable disease burden in 195 countries and territories, 1990-2015: a systematic analysis from the Global Burden of Disease Study 2015. Lancet 2017; 389 (10082): 1885-1906.

24. Forouzanfar MH, Afshin A, Alexander LT, et al. Global, regional, and national comparative risk assessment of 79 behavioural, environmental and occupational, and metabolic risks or clusters of risks, 1990-2015: a systematic analysis for the Global Burden of Disease Study 2015. Lancet 2016; 388: 1659-724.

25. Zatoński WA, Mańczuk M. Tobacco smoking and tobaccorelated harm in the European Union with special attention to the 
new EU member states. In: Tobacco science, policy and public health. Second edition. Boyle P, Gray N, Henningfield J, Sefrin J, Zatoński W. Oxford University Press, Oxford/New York 2010.

26. Zatonski W and HEM project team. Closing the health gap in European Union. The Maria Skłodowska-Curie Memorial Cancer Center and Institute of Oncology, Warsaw 2008.

27. Połtyn-Zaradna K, Zatońska K, Janik-Koncewicz K, et al. Literature review on tobacco smoking in Poland from 1974 to 2020 Bibliographic analysis. J Health Inequal 2020; 6 (2): 104-115.

28. Polakowska M, Kaleta D, Piotrowski W, et al. Tobacco smoking in Poland in the years from 2003 to 2014. Multi-centre National Population Health Examination Survey (WOBASZ). Polish Arch Intern Med 2017; 127 (2): 91-99.

29. Połtyn-Zaradna K, Zatońska K, Basiak A, et al. Sociodemographic characteristic of changes in smoking patterns in rural and urban population of PURE Poland study: findings from 6-year follow up. BMC Public Health 2019; 19 (1): 6.

30. Blanke DD, de Costa e Silva V. Tools for advancing tobacco control in the 21st century. Tobacco Control Legislation: An introductory guide. World Health Organization, Geneva 2004.

\section{AUTHORS' CONTRIBUTIONS}

WZ prepared the concept of the paper. KPZ and KJK analysed data. WZ, KPZ, KJK and MZ interpreted data and wrote the draft manuscript. All authors took part in preparation the final version of the manuscript. 